\title{
PURITAN DAN PEMURIDAN: MIND, HEART AND LIFE IN THE MAKING
}

\author{
Mariani Febriana
}

\begin{abstract}
Abstrak: Pemuridan adalah topik diskusi yang panjang di dalam kehidupan sejarah gereja. Sekarang, banyak pola dan model yang ditawarkan kepada gereja untuk meraih tujuan yang menarik ini, menjadi seorang murid Kristus sejati. Demi mencari pola-pola dan model-model ini kita tidak dapat menghindari tradisi masa lalu gereja dalam menghadapi masalah ini. Salah satu dari tradisi yang luar biasa ini adalah menyuburkan tanah untuk komunitas modern kita sekarang dengan belajar isu-isu ini dari masa Puritan. Kita perlu tradisi Puritan sekarang karena kekayaan tradisi ini akan membantu kita untuk membuat murid-murid Kristus.
\end{abstract}

Visi budaya Puritan adalah untuk membuat pikiran, hati, dan hidup sejalan dengan Firman Tuhan. Visi yang sangat jelas ini dijalankan di dalam setiap aspek kehidupan, dari rumah, gereja, dan masyarakat. Program untuk mencapai tujuan ini adalah sederhana dan dapat diraih. Segala komunitas dilibatkan ke dalam program besar ini. Pelayan-pelayan gereja, para orang tua, dan semua orang percaya adalah sebuah tim untuk mencapai tujuan yang berguna ini dan mereka masing-masing memiliki tanggung jawab. Pembaruan gereja terus ditanam dalam pemuridan supaya setiap orang percaya dibentuk di dalam karakter tuan mereka, sebagai penerus Yesus di dalam kerajaan-Nya.

Kita menyadari bahwa setiap era mempunyai waktunya sendiri-sendiri, namun belajar dari masa lalu dan tradisi yang baik selalu memberikan kepada kita pencerahan yang menginspirasi kita untuk terus melanjutkan tugas yang besar ini di dalam gereja. Gereja adalah seperti seorang penggembara yang berjalan bersama dengan umat Allah di segala zaman dan waktu, dan karena itu gereja tidak seharusnya lupa apa yang telah terjadi dalam kehidupan gereja sebelumnya demi pembelajaran kita pada hari ini. Pembentukan spiritual Puritan yaitu pembentukan pikiran, hati, dan 
hidup untuk menjadi murid-murid Kristus di dunia ini yang memuliakan Tuhan adalah layak menjadi pembelajaran gereja hari ini.

Kata-kata Kunci: Puritan, pemuridan dan pembaharuan gereja, pembentukan pikiran, hati, dan jiwa.

Abstract: Discipleship is the long topic of discussion in the life of the historic church. Today, many patterns and models have been offered to the church in order to reach this magnificent purpose, to be a true disciple of Christ. For the sake of seeking these patterns and models, then we can not ignore the past tradition of how the church dealt with this issue. One of the outstanding tradition that is fertile soil for our modern society to learning this issue is from the Puritan Era. We need this Puritan today because the rich tradition that they had to assist us on making the disciple of Christ.

The cultural vision of the Puritans is to make mind, heart, and life in accord with the word of God. This clearly vision is executed in all the experience of living, from home, church, and society. The program to reach the goal is simple and managable. All the community is involved in this big program. Church Ministers, parents, children, all believers are one team to reach this purposeful aim, and they are having its own responsibility. The renewal of the church is continually instilled in the way of discipleship, so that the believers are formed in the character of their master, as an apprentice of Jesus in Kingdom living.

We realize that every era has its own time, yet learning from this past and outstanding tradition is always giving us insights that inspire us to continue this great task in the church. The Church is like a pilgrim who walk together with all the people of God in all times and ages and therefore the church should not forget what has been done in the life of the church before for the sake of our learning today. The spiritual formation of the Puritan in the matter of making mind, heart, and life for being Christ's disciple in the world that glorifying God is worthy of church learning today. 
Keywords: Puritan, discipleship and church renewal, making mind, heart, and life.

\section{PENDAHULUAN}

Mendengar kata Puritan bisa jadi beberapa teolog akan mengernyitkan dahinya karena kompleksitas persepsi yang dibawa dalam istilah ini. Dalam Sejarah Reformasi Protestan Inggris, Puritan banyak mendapat serangan dan dianggap sebagai kelompok yang paling suci dan karena itu seiring berjalannya waktu, banyak teolog Inggris pada waktu itu merendahkan istilah ini karena dikaitkan dengan kelompok Kathar Abad Pertengahan, suatu kelompok yang memisahkan diri dari gereja Katholik pada permulaan Abad Pertengahan, dengan mengembangkan nilai dan pandangan teologinya yang berbeda dengan gereja pada saat itu. ${ }^{1}$

Istilah yang melekat ini selanjutnya tetap dipakai dengan persepsi yang negatif dalam era Reformasi Protestan Inggris, yang mana penggunaannya justru banyak dipakai oleh para musuh gerakan Reformasi Protestan untuk melemahkan mereka yang berpegang pada pemikiran Reformasi. ${ }^{2}$ Pada tahun 1560 -an, nama yang bersifat ejekan ini diberikan kepada mereka yang berusaha melakukan pemurnian liturgi Anglikan. Mereka dikaitkan dengan apa yang disebut pada hari ini sebagai kelompok Fundamentalis. William Perkins, Bapa dari Puritanisme, menyebutkan bahwa istilah Puritan berkonotasi buruk karena cenderung bersifat sempurna dan karena itu dia lebih cenderung mengunakan istilah saleh. $^{3}$

Meskipun demikian istilah Puritan, namun tetap tidak bisa diabaikan tujuan dan visi mereka dalam Reformasi gereja di Inggris. Generalisasi berpikir negatif tersebut tidak selalu berarti bahwa demikianlah Puritan. Puritan berupaya untuk kembali

\footnotetext{
${ }^{1}$ Randal J. Pederson, Unity in Diversity: English Puritan and the Puritan Reformation 1603-1689 (Leiden: Brill, 2014), p. 26.

${ }^{2}$ Pederson, Unity in Diversity, p. 27.

${ }^{3}$ Joel R. Beeke \& Randall J. Pederson, "Preface," in Meet the Puritans (Grand Rapids: Reformation Heritage Books, 2012), n.p.
} 
kepada Kitab Suci, dan bagaimana Kitab Suci mempengaruhi cara hidup mereka. Karena itu, tepatlah apa yang dikatakan oleh Packer, sebagaimana Beeke mengutip, dalam memahami Puritanisme bahwa Puritanisme itu adalah suatu gerakan kesucian yang menekankan pembaharuan rohani, pribadi, bangsa dan nasional, negara, rumah, pendidikan, penginjilan, ekonomi, dalam pemuridan individu, devosi, dan dalam pelayanan pastoral. ${ }^{4}$

Packer juga menegaskan bahwa visi utama Puritan dalam pelayanan pastoral mereka adalah reformasi umat yang mana esensinya adalah memahami kebenaran, bangkitnya hasrat kudus akan Allah, kerinduan dalam devosi bersama Allah, keteguhan, sukacita, dan cinta kasih dalam menjalani tujuan panggilan kristiani dalam hidup seseorang. Untuk meraih tujuan ini, maka gerakan ini sudah sewajarnya dimulai dengan pelayan Tuhan, yang dalam tulisan Baxter menyebut ini sebagai Reformed Pastor, seorang pelayan yang sudah dibaharui dalam hidup rohaninya. ${ }^{5}$

Nama Puritan paling tidak mendapat persepsi positif pada abad ke-17 dikaitkan dengan perasaan beragama, kelompok antusias, dan bahkan dikaitkan dengan mereka yang hendak memurnikan gereja berkaitan dengan ibadah dan doktrin. Kelompok ini sangat menekankan percakapan rohani pribadi dengan penekanan khusus pada karya transformtif dari Roh Kudus dalam keselamatan.

Kelompok Evangelikal hari ini kembali melirik pikiran-pikiran teologis dalam kelompok ini khususnya perihal pemuridan dan bagaimana cara yang sudah lazim dalam praktek tradisi gereja Protestan ini memberikan kontribusi berharga bagi gereja di abad ke-21 hari ini. Menggali kembali tradisi gereja dalam pola memuridkan menjadi hal yang sangat menarik di tengah arus modern pencarian pola pemuridan gereja. Packer menegaskan bahwa sikap kokoh Puritan mengenai pandangan hidup akan kemuliaan yang akan datang menolong mereka mempersiapkan kematian itu dengan baik dengan menjalani hidup yang benar

\footnotetext{
${ }^{4}$ Beeke \& Pederson, "Preface," Meet the Puritans, n.p.

5 J.I Packer, A Quest for Godliness: The Puritan Vision of the Christian Life (Wheaton, Il: Crossway Books, 1990), pp. 26,27.
} 
sebagai murid Kristus yang setia. ${ }^{6}$ Karena itu, tulisan ini mencoba menolong pembaca menemukan kembali aspek-aspek pola pemuridan dalam gereja yang mungkin terabaikan hari ini dan akan menyegarkan kita kembali untuk menemukan permata yang hilang ini dalam gereja guna melaksanakan tugas pemuridan.

\section{POLA PEMURIDAN PURITAN}

Para Reformator gereja sudah meletakkan visi pelatihan orang percaya guna menjadi murid Yesus yang sejati. Apalagi dalam abad ke-16, pasca Reformasi di seluruh Eropa, mereka sangat membutuhkan orang percaya yang sejati dan setia pada Injil dan karena itu ibadah dan khotbah menjadi tempat di mana proses pembentukan itu terjadi. ${ }^{7}$ Para Puritan menangkap visi ini dan berusaha melakukannya dalam kehidupan sehari-hari dengan memulainya dari rumah dan dalam ibadah bersama. Mungkin ada hal penting yang diwariskan di sini di tengah usaha pemuridan yang dilakukan oleh gereja pada hari ini bahwa pemuridan itu dalam gereja dimulai dari rumah dan menuju ke ruang publik entah itu di gereja atau masyarakat. Artinya, memuridkan itu bukan sekedar mulai di ruang gereja, melainkan mulai di ruang rumah tangga masing-masing dari orang percaya. Karena itu di bawah ini dijabarkan cara bagaimana Puritan membentuk murid yang dipusatkan pada Injil. Mengambil istilah dari Volpe, maka pemuridan itu adalah bagian yang tidak terpisahkan untuk membangun identitas Kristen, karena menjadi murid secara definitif menjadi sama dengan tuannya, dan dalam konteks ini pembentukan menjadi persoalan utamanya. ${ }^{8}$

\section{Pemuridan dalam Keluarga}

Puritan sangat menekankan nilai dan pentingnya pelayanan keluarga. Packer menyebutkan bahwa etika pernikahan Puritan

\footnotetext{
${ }^{6}$ J.I Packer, A Quest for Godliness: The Puritan Vision of the Christian Life, p. 11.

${ }^{7}$ David M. Whitford, (ed), T \& T Clark to Reformation Theology (London: Bloomsbury T \& T Clark, 2014), p. 275.

${ }^{8}$ Medi Ann Volpe, Rethinking Christian Identity: Doctrine and Discipleship (Chichester, West Sussex: Wiley, Blackwell, 2013), p. 228.
} 
bukan untuk mencari partner yang dapat dicintai dengan penuh hasrat diri pada satu waktu, namun seseorang yang dapat dicintai dengan setia sebagai teman terbaik dalam kehidupan serta dengan pertolongan Tuhan melakukan usaha ini. Hal ini disebutkan demikian karena visi mereka adalah mendidik anak dalam jalan yang mereka harus lalui, memperhatikan kebutuhan jasmani dan juga rohani mereka guna mendidik mereka menjadi orang dewasa yang berguna dan saleh. ${ }^{9}$ Di tengah hiruk pikuk kesibukan manusia modern dan membangun pemuridan dari luar, Baxter mengingatkan pentingnya pemuridan yang dimulai dari dalam keluarga orang Puritan. Baxter mengatakan,

We must have a special eye upon families, to see that they are well ordered, and theduties of each relation performed. The life of religion, and the welfare and glory of both the Church and the State, depend much on family government and duty. If we suffer the neglect of this, we shall undo all. What are we like to do ourselves to the reforming of a congregation, if all the work be cast on us alone; and masters of families neglect that necessary duty of their own, by which they are bound to help us? If any good be begun by the ministry in anysoul, a careless, prayerless, worldly family is like to stifle it, or very much hinder it; whereas, if you could but get the rulers of families to do their duty, to take up the work where you left it, and help it on, what abundance of good might be done! I beseech you, therefore, if you desire the reformation and welfare of your people, do all you can to promote family religion. ${ }^{10}$

Memperhatikan kutipan di atas maka sangat jelas bahwa kelesuan orang percaya dan kurang nampaknya transformasi kehidupan gereja dan usaha pembaharuan menuju gereja yang dimuridkan, tidak dimulai dari luar bahkan dari dalam gedung gereja organisasi, melainkan dari dalam gereja secara organisme, dalam keluarga Kristen, yang harus mendapat sentuhan pertama.

\footnotetext{
${ }^{9}$ Packer, A Quest for Godliness, p. 239.

${ }^{10}$ Richard Baxter, Reformed Pastor -The Christian Classic Ethereal Library- (Grand Rapids: Sovereign Grace Pub), p. 47.
} 
Puritan percaya bahwa rumah mereka adalah gereja kecil mereka, sebagaimana Edwards mengatakan bahwa setiap keluarga Kristen seharusnya menjadi suatu gereja kecil, yang dipersembahkan kepada Kristus dan secara penuh diatur dan diperintahkan oleh hukum Kristus. ${ }^{11}$ Bagi orang Puritan, setiap rumah tangga adalah rumah tangga iman, di mana ayah adalah imam dalam keluarganya. Demikian juga keluarga adalah seminari gereja dan negara, karena jikalau anak-anak tidak diberikan prinsip hidup benar di sana maka semuanya akan hancur. ${ }^{12}$

Pemuridan awal dalam keluarga dimulai dari cara dan kehidupan masing-masing pasangan dalam keluarga dan bagaimana ayah dan ibu melakukan tanggung jawab mereka bersama dalam membesarkan dan mendidik anak-anak mereka. Baxter dalam Christian Directory mendorong kaum bapak untuk mengatur keluarga mereka dengan benar dan dalam Reformed Pastor, dia menyerukan agar kaum bapak rajin mengisi diri mereka dengan membaca Kitab Suci dan membaca buku-buku penting untuk memberikan pencerahan dalam membangun keluarga. ${ }^{13}$ Poin penting di sini adalah bagaimana usaha dari bapak-bapak tersebut mengisi diri mereka dengan baik agar mereka juga dapat menolong keluarganya bertumbuh dalam Tuhan. Sarana mengajar yang dipakai di sini adalah dengan menggunakan katekismus. Jadi dalam keluarga kristen, pembentukan pikiran dimulai dengan membuka pemikiran mereka dengan pengajaran yang benar, yang dimulai di rumah, karena dengan mempersiapkan pikiran mereka, maka orang tua sedang membuka jalan kepada hati mereka. ${ }^{14}$ Para bapak dari keluarga Puritan diharapkan memimpin keluarga mereka dalam doa dua kali sehari dan menggali Kitab Suci dan katekismus dengan keluarga mereka paling sedikit pada hari Minggu.

\footnotetext{
${ }^{11}$ Jonathan Edwards, "Farewell Sermon." Works of Jonathan Edwards, Volume One. http://www.ccel.org/e/edwards/works1.i.xxvi.html.

${ }^{12}$ Randy Stinson, Timothy Paul Jones, ed., Trained in the Fear of God: Family Ministry in Theological, Historical, and Practical Perspective (Grand Rapids: Kregel, 2011), p. 121.

${ }^{13}$ Baxter, Reformed Pastor, pp. 47-48.

${ }^{14}$ Ibid. p. 68.
} 
Ayah dan ibu bertanggung jawab penuh sebagai pasangan untuk membangun keluarga mereka. Usaha penting yang dapat dilakukan dan yang tidak dapat diabaikan adalah ibadah keluarga. Ibadah di rumah dan gereja merupakan ibadah antar generasi, tanpa melupakan mendidik generasi itu berdasarkan usia mereka. Belajar dari keluarga Edwards dan Sarah Edwards, setiap hari sang ayah rajin membacakan Kitab Suci untuk anak-anaknya dan mengajarkan mereka katekismus. Setiap hari Sabtu, mereka mempersiapkan anak-anak mereka untuk beribadah pada hari Minggu. ${ }^{15}$

Sekalipun rumah adalah gereja kecil bagi Puritan, namun mereka juga tidak melupakan ibadah publik bersama di gereja. Melalui ibadah publik mereka dipersiapkan juga masuk ke dalam keluarga untuk mendiskusikan katekismus dan khotbah yang sudah didengarkan di gereja. Reformasi gereja mulai dari keluarga dan bukan soal program dan aktivitas bersama dalam gereja. Gereja hendaknya melengkapi umatnya dengan menolong mereka belajar satu keluarga dengan keluarga yang lain dan menolong single parents untuk bertemu dengan keluarga yang lain dalam belajar dalam pemuridan keluarga.

\section{Pemuridan melalui Mimbar Gereja}

Hamba Tuhan memainkan peran penting dalam pemuridan di gereja melalui khotbah dan pengajaran mereka. Khotbah mereka bersifat ekspositoris dengan campuran doktrin dan devosi kepada Kristus. Tanda dari khotbah Puritan adalah menggunakan metode ekspositori, berisi doktrin, teratur dalam susunannya, gayanya populer, berorientasi pada Kristus, bersifat pengalaman, aplikasi yang tajam dan sangat powerful. ${ }^{16}$

Satu kekuatan dari khotbah Puritan adalah karakter intelektualnya. Hal ini tidak berarti bersifat teoritis atau akademis. Tujuan mereka adalah melakukan persuasi akal di mana upaya pemahaman kebenaran yang dinyatakan masuk melalui pengertian

\footnotetext{
${ }^{15}$ Randy Stinson, Timothy Paul Jones, ed., Trained in the Fear of God, p. 126.

${ }^{16}$ Packer, A Quest, pp. 284-288.
} 
dalam akal. Kebenaran itu perlu dipahami baik oleh pengkhotbah maupun pendengarnya. ${ }^{17}$ Khotbah Puritan juga sangat biblikal, karena lahir dari keyakinan mereka akan wibawa dan kuasa dari Kitab Suci, sehingga hanya berita Kitab Suci saja yang mereka sampaikan. Karakter unik mereka juga bersifat teologis dan bahkan sangat pastoral.

Mereka sangat menjiwai khotbah mereka, sehingga kala mereka berkhotbah, Packer menggambarkan bahwa mereka berkhotbah laksana "dying men to dying men," suatu sikap kepedulian yang luar biasa terhadap jiwa orang berdosa. Mereka tidak tertarik dengan membangun reputasi diri sebagai seorang pengkhotbah, sebaliknya mereka sangat dibakar akan kerinduan keselamatan bagi orang berdosa. Dalam berkhotbah, mereka tidak mengandalkan keterampilan mereka bicara, melainkan mereka bersandar penuh pada kekuatan Roh Kudus yang membawa pertobatan dalam diri orang berdosa. Khotbah yang mengubah kehidupan yang tidak dapat dipisahkan dengan kehadiran kuasa ilahi menjadi andalan dari sang pengkhotbah merupakan tekanan yang diberikan oleh Puritan yang dibawa dari John Calvin. ${ }^{18}$

Karena kelompok Puritan berusaha membawa visi Reformasi Calvin di Inggris, maka mereka tidak bisa tidak dapat dipisahkan dari Calvin. Sebagaimana Calvin menaruh perhatian penting dalam berkhotbah bagi pembentukan manusia yang saleh serta bagi perubahan sosial dan memperkuat gereja, maka khotbah atau pelayanan mimbar tidak dapat diabaikan dalam proses pemuridan yang dilakukan oleh Puritan. Dengan ciri khas khotbah yang memang tidak dapat dipisahkan dari cara Calvin berkhotbah, maka Puritan mengembangkan pola "the plain style of preaching."

William Perkins, Bapa Puritan, menjelaskan arti yang dimaksud dengan khotbah yang gamblang itu dengan memperhatikan beberapa hal, yaitu penafsiran yang pas dan benar

\footnotetext{
${ }^{17}$ J.I Packer, Puritan Papers (New Jersey: P \& R Publishing, 2001), p. 220.

${ }^{18}$ Steven J. Lawson, The Expository Genius of John Calvin (Florida: Reformation Trust, 2008), p. 21.
} 
dari Kitab Suci, pengkhotbah mencatat poin-poin dari keseluruhan doktrin dari teks dan menggalinya dan akhirnya pengkhotbah mengaplikasikan doktrin sebagaimana yang ditemukan dalam penggalian teks tersebut, entah itu reformasi mengenai penghakiman atau menyangkut soal reformasi kehidupan. ${ }^{19}$ Sekalipun Perkins dalam khotbahnya sangat nampak nuansa kesarjanaannya, namun dalam khotbahnya, dia tetap menggunakan ekspresi yang lazim bagi para pendengarnya. Secara umum kerangka khotbah Puritan mencakup pendahuluan yang berisikan pernyataan arah dari khotbah yang akan disampaikan, kedua, pengkhotbah menggali teks, doktrin atau topik secara eksposisi; ketiga, melakukan analisa teologis, di mana penghotbah melihat teks itu secara teologis dan kemudian mengaplikasikan khotbah bagi jemaat serta kesimpulan akhir diberikan.

Secara sepintas, khotbah Puritan itu sepertinya membosankan, namun keseriusan mereka terhadap teks Kitab Suci dan keyakinan mereka bahwa Kitab Suci adalah alat anugerah Allah bagi orang berdosa menyebabkan khotbah mereka menjadi unik. Eksplikasi teks menjadi pola yang sangat diperhatikan, meskipun tidak bisa diabaikan juga bahwa khotbah mereka sangat bersifat "experiential." Artinya, khotbah seperti ini adalah khotbah yang menyentuh realitas eksistensial dari umat Allah dan mengaplikasikan teks itu dalam kehidupan kristen yang nyata. ${ }^{20}$ Karena itu, bagi mereka usaha memuridkan pertama-tama adalah dengan membawa seseorang dalam konfrontasi dengan Kitab Suci, khususnya penjelasan Kitab Suci melalui mimbar. ${ }^{21}$

Para Puritan yang sudah mendengarkan Firman Allah diharapkan mendiskusikan firman itu dan mengaplikasikan itu dalam hidup mereka sehari-hari serta mendiskusikan itu seputar meja makan mereka dan di rumah sepanjang minggu. Kepala

\footnotetext{
${ }^{19}$ William Perkins, A Commentary on Galatians, ed. Gerald T. Sheppard (New York: Pilgrim Press, 1989), pp. 140-141.

${ }^{20}$ Joel R Beeke, Puritan Reformed Spirituality (Grand Rapids: Reformation Heritage Books, 2004), pp. 426-428.

${ }^{21}$ Penjelasan mengenai khotbah Puritan dapat dilihat di Joel R Beeke \& Mark Jones, A Puritan Theology: Doctrine for Life (Grand Rapids: Reformation Heritage Books, 2012), pp. 1609-1679.
} 
keluarga bertanggung jawab dengan khotbah yang sudah diterimanya dan mendorong diskusi yang hidup. Bagi pengkhotbah Puritan dengan khotbah yang baik maka mereka akan mendidik jemaat dengan baik dan karena itu diskusi dan melakukannya di keluarga sangat diperhatikan.

Menariknya konsentrasi pengajaran dalam khotbah ibadah Minggu menjadi acuan penting bagi jemaat, di mana selama satu minggu jemaat memikirkan, mencerna, dan berusaha mengaplikasikan itu dalam kehidupan sehari-hari. Bila dibandingkan dengan kondisi gereja pada hari ini maka kesempatan untuk mencerna pengajaran semakin sedikit karena banyaknya kegiatan yang semuanya diberi makan firman, namun terlepas dari maksud yang mau dicapai dari khotbah utama Minggu. Akibatnya, jemaat kebanyakan makan dan menyebabkan gampang sakit dan proses pemuridan menjadi terhambat, atau justru menjadikan orang percaya itu tidak menghargai lagi makanan yang diberikan kepada mereka bahkan bersikap apatis.

\section{Penggunaan Katekismus dan Konfesi Gereja dalam Pemuridan}

Para pengajar Puritan menggunakan juga katekismus, konfesi, dan kredo untuk memuridkan jemaat mereka. ${ }^{22}$ Seperti para Reformator, para Puritan adalah seorang katekis, karena mereka percaya bahwa pelayanan mimbar harus diperkuat dengan pelayanan pribadi melalui katekisasi, yaitu pengajaran doktrin Kitab Suci yang menggunakan katekismus. ${ }^{23}$ Katekismus merupakan alat untuk mengajar jemaat baik tua maupun muda mengenai pokok-pokok dasar dari iman Kristen. Katekismus merupakan ringkasan dasar dari pengajaran gereja dan dengan menggunakan ini para pelayan ditolong untuk mendidik umat dalam dasar-dasar iman.

\footnotetext{
${ }^{22}$ Donald van Dyken, Rediscovering Catechism: The Art of Equipping Covenant Children (New Jersey: P \& R Publishing, 2000), p. 14.

${ }^{23}$ Joel R. Beeke, Puritan Reformed Spirituality (Gand Rapids: Reformation Heritage Books, 2004), p. 160.
} 
Katekisasi menggunakan katekismus merupakan kelanjutan pembinaan dari khotbah di mimbar dan suatu cara untuk menjangkau sesama dengan Injil. Spurgeon menegaskan bahwa penggunaan katekismus dalam keluarga akan menjadi benteng yang kuat dalam melawan kesalahan-kesalahan yang muncul dan untuk tujuan ini, maka kompilasi katekismus dibuat untuk dipakai dalam jemaat. ${ }^{24}$ Bahkan Baxter mengakui bahwa banyak mereka yang tidak mengerti khotbah di mimbar akhirnya mendapatkan banyak pengetahuan setelah diajar menggunakan katekismus, yang merupakan kelanjutan dari khotbah. Karena itu Baxter mengundang jemaat ke rumahnya setiap Kamis malam untuk mendiskusikan dan berdoa atas berkat khotbah yang sudah mereka dengar pada hari Minggu. ${ }^{25}$

Berkaitan dengan penggunaan katekismus di atas memang Puritan sudah mengembangkan katekismus mereka sendiri, yaitu Katekismus Besar Westminster dan Katekismus kecil pada tahun 1640-an. Dalam upaya ini, Baxter mendorong agar setiap kepala keluarga bertanggung jawab dalam mendidik setiap mereka dalam keluarganya $^{26}$ dan para pelayan Tuhan diharapkan menggunakan katekismus ini sebagai bahan pengajaran mereka pada waktu mengunjungi jemaat dari rumah ke rumah. ${ }^{27}$ Berkaitan dengan pemuridan dengan menggunakan katekismus, maka gereja mengeluarkan buku petunjuk untuk dipakai dalam keluarga, khususnya ditujukan untuk orang tua. Pembacaan katekismus dan kredo yang notabene merupakan ringkasan ajaran Kitab Suci menjadi sarana untuk persuasi akal dan hati dalam keluarga.

Penggunaan katekismus, konfesi, dan kredo sebagai sarana bantu dalam mengajar adalah pola yang lazim dalam era Reformasi. Kelaziman ini bukan soal yang baru karena memang tradisi menggunakan katekismus dalam mengajar sudah menjadi kebiasaan gereja sejak Abad Pertengahan, khususnya dalam gereja Katholik. Penggunaan yang umum dari katekismus untuk

\footnotetext{
${ }^{24}$ C.H Spurgeon, Heir of the Puritans diakses dari http://www.spurgeon.org/catechis.php, 18 Januari 2017.

${ }^{25}$ Beeke, Puritan Reformed Spirituality, p. 161.

${ }^{26}$ Baxter, Reformed Pastor, p. 48.

${ }^{27}$ Ibid. p. 9.
} 
pendidikan umat menjadi entry point bagi para petobat baru yang akan masuk dalam komunitas yang bersifat konfesional, karena katekismus dan konfesi memuat pengakuan singkat dari komunitas yang dimasuki oleh petobat baru dan untuk memastikan pengertian dari si petobat baru tentang apa yang dia percayai dan apa yang komunitasnya percayai sebagai dasar iman.

Para Reformator meyakini bahwa orang tua khususnya ayah bertanggung jawab menanamkan prinsip-prinsip iman dalam keluarga. ${ }^{28}$ Sesungguhnya mengajarkan katekismus, dan konfesi di gereja, rumah dan sekolah karena dianggap pentingnya pengertian dan persetujuan kepada apa yang komunitas itu percayai. Dalam suatu era di mana komunitas menjadi sorotan utama dari pada soal individual, maka membagi imannya dalam komunitas justru sama seperti menegaskan identitas kewarganegaraannya. Jadi pengajaran katekismus dan konfesi adalah usaha gereja yang lazim pada saat itu dalam membentuk iman individu yang terikat dalam komunitas.

Dalam keluarga Puritan, orang tua bukan hanya memberikan anak pengetahuan akaliah soal doktrin, namun mereka berusaha untuk mengaplikasikan apa yang sudah mereka pelajari. Kala mereka meminta anak-anak mereka membaca katekismus, maka orang tua berusaha untuk menjelaskan hal tersebut kepada anakanak mereka. Orang Puritan sangat tidak bersahabat dengan kepala yang besar namun hati kecil, isinya banyak di kepala, namun hatinya dingin. Mereka berusaha dan bersandar penuh pada kekuatan Roh Kudus untuk mengejar kekudusan itu dalam hidup secara berimbang.

Keselamatan menjadi tujuan pendidikan mereka dan karena itu orang tua berusaha mengajar dan melakukan apa yang mereka ajarkan. Dalam konteks ini maka ibadah keluarga menjadi bagian yang tidak terpisahkan dalam kehidupan orang Puritan. Dalam ibadah keluarga inilah mereka mengupas Firman Allah dan Kitab Suci dan orang tua memberikan kesempatan kepada anak untuk bertanya dan orang tua akan memberikan penjelasan kepada anak-

${ }^{28}$ Whitford, (ed), T\& T Clark to Reformation Theology, pp. 360-366. 
anak mereka. Pada hari Minggu, ayah akan menuntun diskusi mengenai khotbah Minggu dan melakukan refleksi dalam keluarga apa yang harus mereka lakukan dan apa yang tidak harus mereka lakukan. Karena itu Puritan memperhatikan dengan serius pendidikan dari anak-anak mereka karena ini adalah visi budaya Puritan. Dengan dapat membaca dan mengerti Kitab Suci serta mengajarkan mereka katekismus dan menulis buku khusus bagi anak-anak dan orang muda, mereka berusaha menanamkan visi ini kepada generasi mereka. $^{29}$

\section{Pemuridan Melalui Meditasi, Tulisan Devosional, dan Jurnal Rohani}

Kebanyakan dari orang Puritan adalah penulis yang produktif. Tulisan-tulisan mereka menjadi bahan bacaan bagi para Puritan. Para pendeta Puritan bersikukuh bahwa salah satu bagian menjadi seorang murid Kristus yang baik adalah membaca buku-buku devosi Puritan dan buku-buku yang terkait dengan itu. Tulisan dan jurnal rohani ini tidak dapat dipisahkan dari disiplin mereka dalam merenungkan Firman Allah. Kelompok Puritan percaya bahwa mereka seharusnya memulai hari dengan waktu teduh pribadi untuk berdoa dan merefleksikan kehidupan mereka. Lazimnya refleksi mereka dituliskan dalam suatu jurnal pribadi, yang akan menjadi rujukan mereka dalam melihat pergerakan hidup rohani mereka.

Waktu teduh pagi hari mereka juga menjadi waktu pembaharuan komitmen untuk menghidupi hidup Kristen pada hari yang akan dimasuki. Menjelang hari yang dimasuki, para pemimpin rohani juga mendorong umat membaca buku-buku praktis untuk hidup rohani yang ditulis juga oleh para penulis mereka, dengan tujuan untuk menolong membentuk hidup rohani mereka masing-masing. ${ }^{30}$ Dengan membaca tersebut, mereka

\footnotetext{
${ }^{29}$ Charles Pastoor \& Galen K. Johnson, Historical Dictionary of the Puritans (Lanham: The Scarecrow, 2007), p. 122.

${ }^{30}$ Salah satu petunjuk praktis untuk hidup mereka sehari-hari sebagaimana ditulis oleh Richard Rogers demikian, "I. That we keep a narrow watch over our hearts, words, and deeds continually. 2. That with all care the time be redeemed, which hath beenidly, carelessly, and unprofitably spent. 3. That once in the day at the least, private prayer and meditation (if it may) be used. 5. That our family be with diligence and regard, instructed,
} 
didorong untuk selalu menjaga hati dan pikiran mereka dari serangan dosa yang tidak terduga datangnya. Mengakhiri hari yang dimasuki, mereka juga diharapkan melakukan refleksi mengenai tingkah laku hidup mereka, dengan mengajukan pertanyaan pada diri sendiri sebagai evaluasi diri untuk mengetahui bagaimana mereka sudah menjalani hari mereka. ${ }^{31}$

Kekayaan tulisan devosional mereka yang dilahirkan dari ketekunan membaca Kitab Suci memberikan suatu rahasia di balik khotbah Puritan yang sedemikian membara. George Whitefield, sebagaimana dikutip oleh Packer, menegaskan bahwa para pelayan Tuhan dan pengkhotbah Puritan tidak akan pernah berkhotbah dengan baik sampai mereka menundukan diri mereka di bawah salib, dan Roh Kristus serta kemuliaan-Nya tinggal atas diri mereka. ${ }^{32}$ Tulisan-tulisan mereka tetap memberikan pencerahan bagi manusia modern hari ini mengenai bagaimana mereka mencapai kedewasaan rohani dan menolong manusia modern juga hari ini bagaimana mendisiplinkan diri mereka menuju kedewasaan tersebut. $^{33}$

Sebagaimana ditegaskan di atas bahwa rahasia hidup mereka terletak pada waktu teduh mereka, maka para Puritan tidak pernah lelah untuk mengatakan pentingnya pembacaan dan perenungan Kitab Suci. Dengan meletakkan dasar Kitab Suci dalam waktu teduh mereka, maka mencegah mereka masuk dalam kehidupan rohani yang bersifat mistis, melainkan merenungkan itu untuk dibawa dalam tindakan. Bukannya berkhayal dalam waktu teduh melainkan memikirkan teks yang mereka baca dengan serius. Bagi para Puritan, meditasi merupakan cara untuk melatih pikiran dan akal. $^{34}$ Thomas Watson, seorang penulis Puritan yang dikutip oleh

watched over and governed. 7. That we stir ourselves up to liberality to God's Saints. 8 . That we give not the least bridle to wandering lusts and affections. 10. That we bestow sometime not only in mourning for our own sins, but also for the sins of the time and age wherein we live. 14. That we read somewhat daily of the Holy Scriptures. [Francis J

Bremer, Puritanism: A Very Short Introduction (Oxford: University Press, 2009), p. 55.

${ }^{31}$ Francis J Bremer, Puritanism: A Very Short Introduction, pp. 54-55.

${ }^{32}$ Packer, A Quest, p. 23.

${ }^{33}$ Ibid.

${ }^{34}$ Beeke, Puritan Reformed Spirituality, p.74. 
Beeke, mengatakan bahwa meditasi itu adalah suatu latihan kudus dari pikiran di mana kita membawa Firman Allah untuk selalu diingat, memikirkannya dengan serius dan mengaplikasikan itu bagi diri kita sendiri.

Puritan menuliskan dua macam meditasi, yaitu tulisan yang bersifat berkala dan tulisan yang bersifat perencanaan. Meditasi berkala itu adalah mengamati dengan indera untuk mengarahkan pikiran kita kepada Surga, di mana orang percaya menggunakan indera mereka entah pendengaran, maupun penglihatan sebagai suatu tangga menuju Surga, sebagaimana itu yang Daud lakukan dalam Mazmur 8; Salomo yang memperhatikan semut dalam Amsal 6, dan apa yang Kristus lakukan dengan air di sumur Yakub dalam Yohanes 4. Meditasi seperti ini mudah karena dapat dilakukan di mana saja, kapan saja dan di antara banyak orang. Artinya bahwa manusia yang diarahkan untuk berpikir secara rohani dapat belajar dengan cepat bagaimana memberikan nilai rohani di sekitarnya, karena keinginan mereka dapat dengan cepat berbelok kepada pikiran-pikiran duniawi, yang justru ironisnya dapat menjadikan hal-hal rohani itu menjadi sesuatu yang duniawi.

Meditasi terencana adalah hal yang sangat penting di mana mereka mengambil waktu dan masuk ke dalam kamar serta melakukan perenungan Firman Allah. Dalam konteks meditasi ini, maka Thomas White, penulis Puritan sebagaimana disebutkan oleh Beeke, mencatat bahwa dalam meditasi terencana ini ada empat sumber yang dapat mereka tarik dari meditasi, yaitu Kitab Suci, kebenaran-kebenaran praktis dari kekristenan, peristiwa-peristiwa yang terjadi dalam hidup mereka, dan khotbah yang sudah mereka dengar. Khotbah adalah lahan yang subur untuk dipakai dalam meditasi, karena lebih baik mendengarkan satu khotbah dan merenungkannya daripada mendengarkan dua khotbah tapi tidak pernah merenungkannya. ${ }^{36} \mathrm{Jadi}$ dalam hal ini proses menanamkan khotbah yang sudah didengar adalah dengan mengambil bahan tersebut menjadi tema meditasi pribadi agar berita tersebut benarbenar menyatu dengan kehidupan mereka secara pribadi.

\footnotetext{
${ }^{35}$ Beeke, Puritan Reformed Spirituality, p. 74.

${ }^{36}$ Ibid. p. 77.
} 
Umumnya para Puritan mengakhiri meditasi mereka dengan melakukan pemeriksaan diri, yang terdiri dari pengujian diri, apakah meditasi tersebut dimotivasi oleh iman yang hidup, dan mendorong untuk hidup kudus secara produktif. Kedua, dorongan, yaitu mencakup kepada mereka yang belum percaya dengan sungguh-sungguh sebagai suatu peringatan untuk tidak menggunakan kehidupan bagi tujuan diri sendiri, dan kepada orang percaya mendorong mereka untuk terus merenungkan Firman Allah agar mereka tidak terjebak dalam cara berpikir dunia ini.

\section{Pemuridan Melalui Ibadah Minggu}

Puritan dikenal karena sangat serius memperhatikan hari Sabat, karena bagi mereka sabat itu bukan pilihan melainkan perintah Allah. Cara mereka merayakan hari ini dengan berusaha menjaga agar satu hari ini menjadi hari khusus mereka dalam melakukan aktivitas-aktivitas religius. Secara khusus, hari Sabat atau hari Tuhan seringkali dipakai sebagai hari untuk membangun kesalehan keluarga secara intens. ${ }^{37}$ Keseriusan Puritan dalam memperhatikan hari Sabat, bukanlah untuk ketiadaan aktivitas, namun Sabat merupakan waktu untuk melakukan pekerjaan rohani dalam keluarga. Baxter mengatakan bahwa kepala keluarga bertanggung jawab untuk menolong anggota keluarga mereka mengulangi pembacaan katekismus setiap Minggu malam, dan memberikan mereka beberapa catatan mengenai apa yang sudah mereka dengar dalam ibadah hari tersebut. Pengakuan Iman Westminster bab XXI no. 8 menegaskan apa yang seharusnya dilakukan oleh Puritan ini dalam merayakan sabat, yaitu:

Hari Sabat ini harus dikuduskan bagi Allah, ketika manusia, setelah mempersiapkan hati mereka dengan benar dan telah mengurus kegiatan umum mereka sebelumnya, tidak hanya mematuhi suatu perhentian kudus sepanjang hari dari pekerjaan-pekerjaan, kata-kata, dan pikiran-pikiran mereka tentang pekerjaan dan rekreasi dunia, tetapi juga harus menggunakan seluruh waktu untuk beribadah kepada-Nya

${ }^{37}$ Bremer, Puritanism: A Very short Introduction, p. 64. 
dalam pelaksanaan secara bersama maupun pribadi, dan dalam melakukan pekerjaan yang merupakan keharusan, dan pekerjaan untuk belas kasih. ${ }^{38}$

Karena keseriusan memperhatikan hari ini, maka persiapan itu sudah dimulai dari rumah tangga, dengan doa keluarga dan perenungan. Setelah persiapan itu maka keluarga Puritan berkumpul bersama di gereja untuk ibadah bersama. Kebanyakan dari mereka membawa Kitab Suci, dan juga buku catatan serta pena untuk mencatat khotbah yang didengar. Pencatatan ini bertujuan untuk mendiskusikan khotbah itu kembali dengan keluarga dan sesama orang percaya. ${ }^{39}$ Pada umumnya, perayaan sabat di Inggris dan Inggris Baru dibuka dengan doa pembukaan, pembacaan dan eksplikasi teks, jemaat menyanyi Mazmur dan khotbah diperdengarkan. Dalam beberapa kasus jemaat diizinkan bertanya setelah khotbah untuk mengklarifikasi berita yang mereka dengar atau memberikan kesaksian mereka. Doa dan berkat akan mengakhiri ibadah mereka. ${ }^{40}$

Proses pemuridan terjadi dalam ibadah, dan pasca ibadah khususnya pertemuan mereka satu sama lain untuk mendiskusikan firman yang sudah mereka dengar. John Cotton, seorang pelayan di New England, mendorong jemaat untuk mencari kelompok kecil mereka, yang akan menjadi rekan rohani mereka dalam perjalanan dan mendukung mereka dalam menghadapi masa sulit dalam hidup. Richard Rogers juga mendorong orang percaya untuk berkumpul secara rutin dalam kelompok untuk dapat saling memperkuat dalam iman. Bukan hanya jemaat yang berkumpul, bahkan kaum rohaniwan juga didorong untuk berkumpul guna berdiskusi satu sama lain. Lazimnya kala mereka berkumpul mereka berbagi pengalaman rohani mereka, yang sudah menyegarkan mereka dan membangkitkan kembali semangat rohani mereka untuk selalu dibaharui. Beberapa dari kelompok

\footnotetext{
${ }^{38}$ Pengakuan Iman Westminster, diakses dari sinodegkim.com/wpcontent/uploads/.../PENGAKUAN-IMAN-WESTMEINSTER.pdf, 25 Januari 2017.

${ }^{39}$ Bremer, Puritanism: A Very short Introduction, p. 66.

${ }^{40}$ John Coffey and Paul C.H. Lim, ed. The Cambridge Companion to Puritanism (Cambridge: University Press, 2008), p. 132.
} 
mereka dipimpin oleh pendeta jemaat. ${ }^{41}$ Tujuan dari pendeta hadir dalam kelompok kecil ini, sebagaimana Baxter mencatat adalah agar pendeta lebih memahami jemaat mereka dan mengetahui dengan baik bagaimana menggembalakan mereka, berkhotbah bagi mereka, meratapi bersama mereka, dan bersuka bersama mereka serta berdoa bagi mereka dalam menghadapi pergumulan kehidupan mereka sehari-hari.

\section{Puritan dan Pemuridan}

Beranjak dari pembahasan di atas, maka sangat penting hari ini orang percaya belajar dari mereka, khususnya bagaimana seorang Puritan mewujudkan visi membangun komunitas orang percaya yang terus dibaharui. Packer menegaskan bahwa manusia modern hari ini sangat membutuhkan mereka, khususnya orang kristen di Barat yang selalu mengasosiasikan mereka dengan naif, tahyul, primitif, selalu tegang dan tidak rileks. Orang percaya perlu belajar dari mereka karena kematangan rohani mereka, yang dikaitkan dengan hikmat, kemauan baik, ketenangan, dan kreativitas. Dalam diri seorang Puritan, tergabung semangat keteguhan dalam ajaran dan kehangatan hati dalam hidup. mereka juga adalah kelompok yang kokoh dalam visi dan praktis, bersifat idealistik namun juga realistik, ditujukan pada tujuan dan penggunaan metode, mereka adalah orang percaya yang luar biasa, pengharap yang kokoh kepada Allah, pelaku yang luar biasa, dan mereka juga berani menderita. Mereka juga kaya dalam pengalaman rohani mereka, hasrat mereka yang tinggi akan tindakan yang efektif, program mereka untuk kestabilan dalam keluarga, penghargaan terhadap martabat diri dan idealisme mereka bagi pembaharuan gereja. ${ }^{42}$

Visi pembaharuan Puritan di atas mengajarkan banyak hal bagi gereja pada hari ini. Jikalau kita dapat meminjam istilah yang bersifat definitif dari Simple Church, maka pemuridan ala orang Puritan di atas adalah sebenarnya apa yang menjadi mimpi dari

\footnotetext{
${ }^{41}$ Bremer, Puritanism: A Very short Introduction, pp. 67-68.

${ }^{42}$ Packer, A Quest, pp. 22-27.
} 
penulis Simple Church. Rainer dan Geiger mendefinisikan Simple Church demikian,

A simple church is designed around a straightforward and strategic process that moves people through the stages of spiritual growth. The leadership and the church are clear about the process (clarity) and are committed to executing it. The process flows logically (movement) and is implemented in each area of the church (alignment). The church abandons everything that is not in the process (focus). ${ }^{43}$

Elemen penting dari proses pemuridan dalam definisi di atas adalah gerakan umat, kepemimpinan dan gereja yang mengarah pada visi atau fokus atau pemuridan. Unsur-unsur ini sangat kaya dalam diskusi pemuridan Puritan di atas dengan visi budaya komunitas kristen yang mereka harapkan. Dalam diskusi mengenai Doctrine, Discipleship and Christian identity, Volpe menegaskan bahwa ada suatu keterikatan yang kuat di antara ketiga bagian ini, di mana identitas yang kuat dari seorang Kristen adalah menjadi murid yang mengikuti tuannya, yang didasarkan kuat pada ajaran Kitab Suci. ${ }^{44}$ Jadi tidak heran bahwa betapa pentingnya orang percaya hari ini belajar dari Puritan dan memang orang percaya sangat membutuhkan teladan mereka dalam membangun identitas Kristen hari ini di tengah ketidakjelasan orang percaya dalam kehadirannya di tengah bangsa hari ini.

Beberapa hal penting yang dapat dipelajari dan yang mungkin terlupakan pada hari ini mengenai pemuridan adalah kegigihan Puritan untuk membangun identitas kristen ini yang dimulai dari rumah. Bagi mereka, home-based discipleship adalah titik awal yang tidak biasa diabaikan dalam membangun proses pemuridan. Usaha gereja yang terkonsentrasi pada gereja hari ini, memang sangat baik, namun kekuatan dari church-based discipleship ini akan mencapai tujuannya secara komunal jikalau pendekatan ini juga menyentuh pada ranah eksistensial dari keluarga kristen, yang

\footnotetext{
${ }^{43}$ Thom S. Rainer \& Eric Geiger, Simple Church: Returning to God's Process for Making Disciple (Word Serach Corporation, 2006), p. 41.

${ }^{44}$ Volpe, Rethinking Christian Identity, pp. 222-241.
} 
justru banyak mendapat tantangan dan serangan dalam dunia pada hari ini.

Artinya home-based discipleship ini tidak berarti mengeliminir community or church-based discipleship yang dilakukan dalam gereja pada hari ini. Para Puritan menyadari tantangan besar bagi keluarga kristen ini dan karena itu bagi mereka usaha memuridkan itu harus mulai dari rumah karena karakter sejati kita terbentuk pertama dari rumah dan yang menyaksikan itu adalah orang terdekat di rumah. Di dalam rumah, kehidupan rohani itu teruji pada titik awal awal apakah itu akan bertumbuh atau runtuh. ${ }^{45}$ Memang idealisme Puritan tidak dapat kita hidupi pada hari ini secara per se, namun paling tidak ada suatu dorongan dan tanggung jawab baru sekarang dalam diri orang percaya dan gereja dalam membangun pemuridan bahwa rumah keluarga Kristen tidak dapat diabaikan dalam menghadapi derasnya serangan zaman terhadap persoalan dan konflik dalam keluarga kristen hari ini.

Visi pemuridan dari rumah sudah ditangkap juga oleh gereja Baptis West Virginia di mana proses pembentukan murid itu dimulai sejak anak dilahirkan, dan rumah adalah perjalanan panjang kehidupan di mana ayah, ibu, dan anak-anak belajar, berbagi, dan berjalan dalam perarakan rohani bersama-sama, dengan menyesuaikan kondisi keluarga masing-masing. ${ }^{46}$ Pengembangan kelompok kecil yang mulai dari keluarga dan sesama anggota gereja sebagai ruang diskusi pengalaman hidup yang penting untuk menguatkan dan menyegarkan perjalanan rohani orang percaya sudah menjadi acuan penting juga dalam pemuridan yang justru sudah banyak dikembangkan dalam pola pemuridan modern hari ini.

Willard juga mengingatkan bahwa jangan sampai tanggung jawab penting ini justru diberikan ke luar gereja, sebagaimana kritikan tajam diberikan olehnya bahwa pada kenyataannya banyak

\footnotetext{
${ }^{45}$ Beeke, A Puritan Theology, 1373.

${ }^{46}$ West Virginia Baptist Convention, Household Discipleship Resource for the Local Church, (Parkersburg, WV: Discipleship Ministries, 2016), 14-15. Diakses dari www.wvbc.org/wp-content/uploads/2016/12/HDR2016.pdf, tanggal 26 januari 2017.
} 
gereja Evangelikal menyerahkan proses pemuridan ini bukan kepada lokal melainkan kepada organisasi parachurch karena dianggap pemuridan bukan menjadi tugas yang seharusnya dari gereja. Pemikiran ini disebabkan karena adanya asumsi yang meluas di luar kaum evangelikal bahwa kita dapat menjadi kristen tanpa menjadi murid. Padahal sejatinya menjadi murid adalah murid dari Yesus dalam kehidupan kerajaan. ${ }^{47}$ Sebagaimana demikianlah visi Puritan dalam kehidupan, yaitu membawa nilainilai kerajaan Allah itu termanifestasi dalam kehidupan, yang diawali dengan pembentukan pikiran melalui devosi diri dan keluarga dan membangun hasrat kudus dalam kehidupan kepada Allah dan sesama.

\section{KESIMPULAN}

Beranjak dari diskusi di atas, maka pemuridan menjadi tugas penting dalam hidup gereja. Pemuridan menjadi jalan pembentukan jati diri dan identitas kristen. Memperhatikan keseriusan orang Puritan dalam mempersiapkan umat Allah menjadi murid Yesus yang tangguh dalam dunia, patut menjadi pembelajaran gereja pada hari ini sekalipun ada tegangan waktu yang jauh dengan era di mana mereka hidup.

Meskipun ada kesenjangan zaman demikian, namun prinsipprinsip yang memperkaya cara pemuridan gereja hari ini dapat diambil dari pendekatan Puritan dalam pemuridan. Bergerak dari rumah menuju kepada gereja dan memberikan dampak dalam hidup masyarakat tentu menjadi sasaran penting dari kehadiran umat Allah dalam dunia. Kehadiran yang memperkaya kehidupan yang benar sejatinya berawal dari keluarga dan gereja, agar banyak orang melihat perbuatan baik kita dan memuliakan Bapa kita di Sorga.

\footnotetext{
${ }^{47}$ Dallas Willard, The Great Omission: Reclaiming Jesus's Essential Teaching on Discipleship (Harper Collins e-book, n.d), p. 166.
} 


\section{DAFTAR RUJUKAN}

Baxter, Richard. Reformed Pastor -The Christian Classic Ethereal Library- Grand Rapids: Sovereign Grace Pub.

Beeke, Joel R. \& Pederson, Randall J. "Preface," in Meet the Puritans. Grand Rapids: Reformation Heritage Books, 2012.

Beeke, Joel R. \& Jones, Mark. A Puritan Theology: Doctrine for Life. Grand Rapids: Reformation Heritage Books, 2012.

Beeke, Joel R. Puritan Reformed Spirituality. Grand Rapids: Reformation Heritage Books, 2004.

Bremer, Francis J. Puritanism: A Very Short Introduction. Oxford: University Press, 2009.

Coffey, John and Lim, Paul C.H.ed. The Cambridge Companion to Puritanism. Cambridge: University Press, 2008.

Dyken, Donald van. Rediscovering Catechism: The Art of Equipping Covenant Children. New Jersey: P \& R Publishing, 2000.

Lawson, Steven J. The Expository Genius of John Calvin. Florida: Reformation Trust, 2008.

Packer, J.I. A Quest for Godliness: The Puritan Vision of the Christian Life. Wheaton, Il: Crossway Books, 1990.

Packer, J.I. Puritan Papers. New Jersey: P \& R Publishing, 2001.

Pastoor, Charles \& Johnson, Galen K. Historical Dictionary of the Puritans. Lanham: The Scarecrow, 2007.

Pederson, Randal J. Unity in Diversity: English Puritan and the Puritan Reformation 1603-1689. Leiden: Brill, 2014. 
42 Puritan Dan Pemuridan: Mind, Heart And Life In The Making

Perkins, William. A Commentary on Galatians, ed. Gerald T. Sheppard. New York: Pilgrim Press, 1989.

Rainer, Thom S. \& Geiger, Eric. Simple Church: Returning to God's Process for Making Disciple. Word Serach Corporation, 2006.

Stinson, Randy, Jones, Timothy Paul. ed. Trained in the Fear of God: Family Ministry in Theological, Historical, and Practical Perspective. Grand Rapids: Kregel, 2011.

Volpe, Medi Ann. Rethinking Christian Identity: Doctrine and Discipleship. Chichester, West Sussex: Wiley, Blackwell, 2013.

Whitford, David M. ed. $T \& T$ Clark to Reformation Theology. London: Bloomsbury T \& T Clark, 2014.

Willard, Dallas. The Great Omission: Reclaiming Jesus's Essential Teaching on Discipleship. Harper Collins e-book, n.d.

\section{INTERNET}

C.H Spurgeon. Heir of the Puritans diakses dari http://www.spurgeon.org/catechis.php tanggal 18 Januari 2017.

Edwards, Jonathan. "Farewell Sermon." Works of Jonathan Edwards, VolumeOne. http://www.ccel.org/e/edwards /works1.i.xxvi.html.

Pengakuan Iman Westminster. diakses dari sinodegkim.com/wpcontent/uploads/.../PENGAKUAN-IMANWESTMEINSTER.pdf, tanggal 25 Januari 2017.

West Virginia Baptist Convention. Household Discipleship Resource for the Local Church, (Parkersburg, WV: Discipleship Ministries, 2016), 14-15. Diakses dari www.wvbc.org/wpcontent/uploads/2016/12/HDR2016.pdf, tanggal 26 januari 2017. 